Hindu-Frauen zwischen Tradition und Moderne 
Ergebnisse der Frauenforschung

Band 57

Begründet und im Auftrag des Präsidenten der Freien Universität Berlin herausgegeben von

Prof. Anke Bennholdt-Thomsen, Germanistik

Dr. Ulla Bock, Soziologie

Prof. Marlis Dürkop, Sozialpädagogik

Prof. Ingeborg Falck, Medizin

Prof. Dr. Ingrid Kasten, Mediävistik

Prof. Marion Klewitz, Geschichtsdidaktik

Prof. Jutta Limbach, Jura

Prof. Hans Oswald, Pädagogik

Prof. Renate Rott, Soziologie

Dr. Hanna Beate Schöpp-Schilling,

Amerikanistik/Anglistik, Germanistik

Prof. Dr. Irmingard Staeuble, Psychologie

Prof. Margarete Zimmermann, Romanistik

Koordination: Dr. Anita Runge 
Katharina Poggendorf-Kakar

\title{
HINDU-FRAUEN ZWISCHEN TRADITION UND MODERNE
}

\author{
Religiöse Veränderungen \\ der indischen Mittelschicht im städtischen Umfeld
}

Verlag J. B. Metzler

Stuttgart - Weimar 
Die Deutsche Bibliothek - CIP-Einheitsaufnahme

Poggendorf-Kakar, Katharina:

Hindu-Frauen zwischen Tradition und Moderne/Katharina Poggendorf-Kakar

- Stuttgart ; Weimar : Metzler, 2002

(Ergebnisse der Frauenforschung ; Bd. 57)

(M-\&-P-Schriftenreihe für Wissenschaft und Forschung)

ISBN 978-3-476-45283-2

ISBN 978-3-476-02916-4 (eBook)

DOI 10.1007/978-3-476-02916-4

Dieses Werk einschließlich aller seiner Teile ist urheberrechtlich geschützt. Jede Verwertung außerhalb der engen Grenzen des Urheberrechtsgesetzes ist ohne Zustimmung des Verlages unzulässig und strafbar. Das gilt insbesondere für Vervielfältigungen, Übersetzungen, Mikroverfilmungen und die Einspeicherung und Verarbeitung in elektronischen Systemen.

M \& P Schriftenreihe für Wissenschaft und Forschung

(C) 2002 Springer-Verlag GmbH Deutschland Ursprünglich erschienen bei J. B. Metzlersche Verlagsbuchhandlung und Carl Ernst Poeschel Verlag GmbH in Stuttgart 2002 


\section{INHALT}

VoRWORT $\ldots \ldots \ldots \ldots \ldots \ldots \ldots \ldots \ldots$

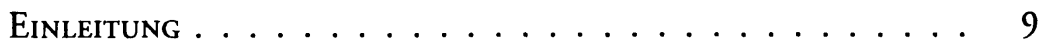

Erster TeIL: Hinduistische WeiblichKeitsVorstellungen im KULTURELLEN KONTEXT

1. Die sich wandelnde Frau: Das soziale Umfeld pan-indischer Mittelklassefrauen . . . . . . . . . . . . . . . . . 2 21

2. Das Auslaufmodell Sïtā: Gesellschaftliche Transformationsprozesse und Veränderungen religiöser Leitbilder. . . . . . . . . . . . 40

3. Gattin, Göttin, Mutter: Religiöse Konzepte und soziale

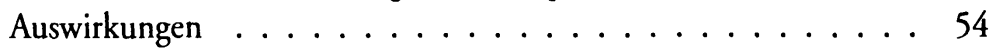

Zweiter Teil: Die ENTSTEhUNG ReligiöSER IDENTItät IM LEBENSUMFELd STÄDTISCHER FraUeN

4. Häusliche Transformationsprozesse: die Fastenpraxis Karvā Chauth. 95

5. Außerhäusliche Transformationsprozesse: Die Pilgerstätte Vaisno Devis . . . . . . . . . . . . . . . . . . . . . 110

6. Die Entstehung neuer Kultformen: Der Kinofilm যai Santoși Māa . 127

7. Die Entstehung neuer Kultformen: Die ^New Ages-Bewegung . . . 151

Dritter Teil: ANTworten /Religiöser Feministinnen im HINDUfUNDAMENTALISTISCHEN SPEKTRUM

8. Facetten indischer Feminismen . . . . . . . . . . . . . . 175

9. Die Hinwendung von Frauen zu hindufundamentalistischen Bewegungen der Gegenwart . . . . . . . . . . . . . 187

10. Asketinnen und mātājūs als Träger religiöser Feminismen?? . . . . . 213

11. Ideale ,weiblicher Macht und die Kontrolle von Frauen . . . . . 219

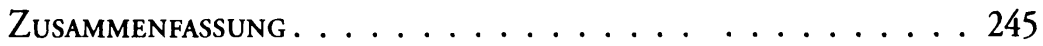

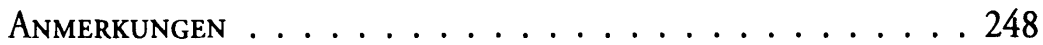

LiterATURVERZEICHNIS . . . . . . . . . . . . . . . . . 271

Glossar . . . . . . . . . . . . . . . . . 292 
Für Imme 


\section{VORWORT}

"Es gibt eine indische Geschichte [...] über einen Engländer, dem man erklärt hatte, die Welt stehe auf einem Podest, das auf dem Rücken eines Elefanten stehe, der selbst wiederum auf dem Rücken einer Schildkröte stehe; und dieser Engländer fragte daraufhin [...], worauf denn die Schildkröte stehe? Auf einer anderen Schildkröte. Und diese andere Schildkröte? ,Oh Sahib, dann kommen nur noch Schildkröten, immer weiter hinunter.." (Geertz, 1997: 41)

Auch die Welt der Frauen, die den Mittelpunkt der vorliegenden Studie bildet, steht auf einem Podest unzählbar vieler Schildkröten. Es werden im folgenden jedoch keine Schildkröten gezählt, sondern Lebensgeschichten, Erfahrungen und Vorstellungen in einen Kontext gestellt, um den Lesern und Leserinnen einen Zugang zu der Welt und dem Denken städtischer Mittelklassefrauen zu ermöglichen. Dabei stütze ich mich auf umfangreiches Interviewmaterial zur sozio-religiösen Situation städtischer Frauen der indischen Mittelklasse, einer in der Südasienforschung weitgehend vernachlässigten Schicht.

Die auf einer zweijährigen Feldforschung basierende Studie wurde mit einem Stipendium der Berliner Senatsverwaltung für Arbeit, Berufliche Bildung und Frauen, Förderprogramm Frauenforschung ermöglicht. Für die großzügige Unterstützung möchte ich meinen Dank aussprechen. Die Ergebnisse der Arbeit wurden im Juni 2001 in etwas veränderter Fassung als Dissertation an der Freien Universität Berlin eingereicht. Herrn Professor Hartmut Zinser vom Institut für Religionswissenschaft der Freien Universität Berlin und Herrn Professor Axel Michaels vom Südasien-Institut der Universität Heidelberg danke ich, mich im Verlauf der Promotion begleitet und stets hilfreich in meinen Ideen unterstützt zu haben. Auch der Edition 'Ergebnisse der Frauenforschung and der FreienUniversität Berlinı, Zentraleinrichtung zur Förderung von Frauen- und Geschlechterforschung, die die vorliegende Publikation ermöglicht hat, möchte ich herzlich danken.

Shalu Bhardwaj, Vaishali Tayagi und Shruti Sharma danke ich, mir während der Feldforschung zu unterschiedlichen Zeitpunkten sowohl bei der Gesprächsführung als auch bei der Übersetzung und Transkription von Interviews kompetent und hilfreich zur Seite gestanden zu haben. Allen Interviewpartnerinnen, die mich mit großer Offenheit und Selbstverständlichkeit an ihrer Lebenswelt teilnehmen ließen, sei an dieser Stelle ebenso herzlichst gedankt. Die vielseitige Unterstützung von meiner Familie, Freundinnen, Freunden, Kolleginnen und Kollegen in Berlin und Delhi hat den Verlauf der 
Arbeit zu einer erlebnisreichen Reise werden lassen. Insbesondere meinem Mann Sudhir Kakar möchte ich herzlich danken für die vielen Stunden, in denen er mich bekochte und umsorgte, mir zuhörte und in Gesprächen weiterhalf.

Die Arbeit ist meiner Freundin Imme Waßmund gewidmet, die im Zeitraum der Fertigstellung des Manuskripts tödlich verunglückte.

Übersetzungen von Hindi- und Sanskritausdrücken im Text sind mit den üblichen diakritischen Zeichen versehen, mit Ausnahme von Orts- und Personennamen. Für die diakritische Zeichensetzung wurde sich an McGregors Oxford Hindi-Englisch Dictionary orientiert. Begriffe in Zitaten wurden so zitiert, wie in der Textquelle vorgegeben, so dass es zu Abweichungen von der im Text verwendeten Sprachform kommt. Die im Text vorkommenden Hindi- und Sanskritbegriffe sind im Anhang im Glossar aufgelistet und definiert. 